\title{
A PERCEPÇÃO DOS VIAJANTES LOCATÁRIOS DE VEÍCULOS SOBRE A SINALIZAÇÃO DE ORIENTAÇÃO TURÍSTICA DE NATAL-RN
}

\author{
THE PERCEPTION OF TOURISTS DRIVING HIRE CARS, OF TOURIST SIGNAGE IN NATAL, RN \\ LA PERCEPCIÓN DE LOS VIAJEROS LOCATARIOS DE VEHÍCULOS SOBRE LA SEÑALIZACIÓN \\ TURÍSTICA DE NATAL, RN
}

\author{
Viviane Paula da Silva \\ Graduada em Turismo \\ Universidade Federal do Rio Grande do Norte \\ viviane.paularn@gmail.com
}

Cleber Augusto Trindade Castro Doutorando em Turismo, Mestre em Geografia Universidade Federal do Rio Grande do Norte cleber.at.castro@gmail.com

Data de Submissão: 06/10/2016 Data de Aprovação: 19/06/2017

RESUMO: A finalidade de uma sinalização, seja essa de indicação de trânsito ou de orientação turística, é orientar os usuários das vias urbanas e rurais, auxiliando-os e direcionando-os a atingir os destinos pretendidos. A sinalização de orientação turística, em particular, pretende informar a existência de atrativos e serviços turísticos em um destino, além das rotas que os turistas podem percorrer para acessar esses elementos, por isso tem função importante no uso dos espaços turísticos. Portanto, este trabalho teve o objetivo de compreender a percepção dos viajantes locatários de veículos sobre a sinalização de orientação turística em Natal-RN. Além disso, buscou-se verificar o grau de satisfação desses visitantes sobre esse serviço prestado pela cidade. Foi realizada uma pesquisa empírica exploratória, por meio da aplicação de questionários com perguntas objetivas e fechadas no Aeroporto Internacional de Natal. Os dados foram analisados utilizando princípios da estatística descritiva. Os resultados da pesquisa apontam uma percepção positiva sobre a existência da sinalização turística e um alto grau de satisfação com esse aspecto da infraestrutura da cidade. No entanto, a percepção positiva da sinalização turística diminui quando são consideradas dimensões relacionadas à continuidade e à eficiência dessa estrutura em orientar os deslocamentos dos visitantes pela cidade.

PALAVRAS-CHAVE: Sinalização Turística. Infraestrutura turística. Espaço Urbano Turístico.

ABSTRACT: The purpose of signage, whether for the purpose of guiding traffic or tourists, is to direct users of urban and rural routes, helping them reach their intended destinations. Tourist signage, in particular, aims to inform tourists the existence of attractions and tourist services at a destination, and routes that tourists can take to reach these places. Signage therefore has important function in the use of the tourist spaces. This work aims to understand the perceptions of tourists driving hired cars, of the tourist signage in Natal, RN. It also seeks to determine the degree of satisfaction of these visitors with this service provided by the city. Exploratory empirical research was carried out through the application of questionnaires with objective and closed questions, at Natal International Airport. The data were analysed using principles of descriptive statistics. The research results indicate a positive perception of the tourist signage, and a high degree of satisfaction with this aspect of the city's infrastructure. However, the positive perception of tourist signage diminishes when dimensions are included related to the continuity and efficiency of this structure to direct visitors, as they transit around the city.

KEYWORDS: Tourist Sign. Tourist Infrastructure. Tourist Urban Space. 
RESUMEN: La finalidad de una señalización, ya sea de indicación de tránsito o turística, es orientar a los usuarios de las vías urbanas y rurales, auxiliándolos y dirigiéndolos a alcanzar los destinos pretendidos. La señalización turística, en particular, pretende informar la existencia de atractivos y servicios turísticos en una destinación, además de las rutas que los turistas pueden recorrer para acceder a esos elementos, por lo que tiene una función importante en el uso de los espacios turísticos. Así pues, este trabajo tuvo el objetivo de comprender la percepción de los viajeros locatarios de vehículos sobre la señalización turística en Natal, RN. Además, se buscó verificar el grado de satisfacción de esos visitantes sobre ese servicio prestado por la ciudad. Se realizó una investigación empírica exploratoria, a través de la aplicación de cuestionarios con preguntas objetivas y cerradas, en el Aeropuerto Internacional de Natal. Los datos se analizaron utilizando los principios de la estadística descriptiva. Los resultados de la investigación apuntan una percepción positiva sobre la existencia de la señalización turística y un alto grado de satisfacción con ese aspecto de la infraestructura de la ciudad. Sin embargo, la percepción positiva de la señalización turística disminuye cuanto se consideran dimensiones relacionadas a la continuidad y a la eficiencia de esa estructura en orientar los desplazamientos de los visitantes por la ciudad.

PALABRAS CLAVE: Señalización turística. Infraestructura turística. Espacio Turístico Urbano.

\section{INTRODUÇÃO}

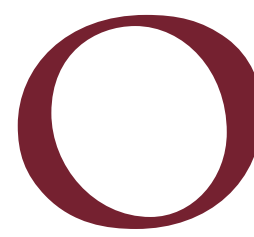

turismo, como uma das principais atividades sociais e econômicas do mundo contemporâneo, é uma atividade que tem a capacidade de trazer inúmeros benefícios tanto para o turista quanto para a comunidade receptora; isso porque o turismo contribui para a valorização de aspectos da cultura local e impulsiona a economia em diversos setores, contribuindo, assim, para o desenvolvimento socioeconômico das destinações turísticas.

Contudo, os destinos turísticos precisam possuir uma estrutura adequada para atender às necessidades básicas dos turistas. Por isso, torna-se imprescindível que essa estrutura seja planejada nas áreas de interesse turístico.

Isso implica a oferta de uma infraestrutura básica, bem como instalações de alguns equipamentos e serviços turísticos, como o de energia elétrica, água, esgoto, transporte, comunicação, meios de hospedagem, alimentação etc., que se fazem necessários para que o turista possa manter condições básicas de estada e locomoção nas cidades.

Diante disso, uma atenção especial deve ser dada aos investimentos na infraestrutura referentes ao sistema viário e de transporte local, visto que estes também são de fundamental importância para o desenvolvimento socioeconômico de uma região e que integram um importante componente da infraestrutura básica necessária para a realização do turismo, pois sem 
condições básicas de acesso e meios de transporte, o mesmo não é capaz de existir (Barretto, 1991).

Faz parte da infraestrutura desse sistema viário a sinalização, que é essencial para auxiliar os turistas em seus deslocamentos dentro de determinada região. Essa sinalização, tanto de indicação de trânsito quanto de orientação turística, tem por finalidade orientar e auxiliar os usuários dos espaços públicos urbanos para que possam chegar aos lugares pretendidos de uma forma objetiva e segura.

Entretanto, a sinalização de orientação turística apresenta algumas peculiaridades diferentes das demais. Esse tipo particular de sinalização é voltado principalmente para o turista, portanto, além de orientar e direcionar, objetiva ainda informar a existência de serviços e atrativos de interesse turístico numa determinada área, bem como informações importantes que auxiliam a experiência turística.

Desse modo, a sinalização turística tem função importante no uso dos espaços turísticos de uma cidade, pois é através dela que o turista tem autonomia para trafegar por um local sem ter que depender de mapas ou guias, ou como complemento a estes.

Na cidade de Natal-RN, a atividade do turismo tem possibilitado vários investimentos em infraestrutura. A Copa do Mundo de 2014 foi um exemplo de evento que proporcionou alguns investimentos na cidade buscando melhorias na sua estrutura para atender à demanda dos turistas que estiveram na região. Vários projetos e investimentos de mobilidade urbana começaram a ser implantados na cidade, desde a construção de calçadas acessíveis para passeios públicos, até mesmo a implantação de sinalização turística, de trânsito e de ruas. Porém a cidade continua carecendo de melhorias na sua infraestrutura e a sinalização turística se encontra nesse contexto.

Em uma pesquisa realizada pelo Ministério do Turismo (MTUR), em parceria com o Serviço de Apoio às Pequenas Empresas (SEBRAE) e a Fundação Getúlio Vargas (FGV), sobre o Índice de Competitividade do Turismo Nacional, em 2015, foi observado que os principais desafios que a cidade de Natal-RN ainda enfrenta em relação à sinalização turística é justamente, "a ausência de sinalização turística viária em idioma estrangeiro; inexistência de sinalização 
turística descritiva ou interpretativa nos atrativos, bem como de placas com mapa turístico informativo nas áreas turísticas". (MTUR, 2015, p. 21).

Diante desse contexto, o presente estudo teve como objetivo compreender a percepção dos viajantes locatários de veículos sobre a sinalização de orientação turística em Natal-RN. Além disso, buscou-se verificar o grau de satisfação desses visitantes sobre esse serviço prestado pela cidade.

Esta pesquisa é relevante diante do crescente aumento de turistas que a cidade de Natal-RN vem recebendo ao longo dos anos e, nesse contexto, a sinalização turística é um importante aspecto para que a experiência dos turistas seja satisfatória, contribuindo para uma boa imagem da cidade como destinação turística diante do contexto da competição dos lugares para receberem fluxos de turistas.

O trabalho contribui, por um lado, como subsídio à tomada de estratégia por parte das políticas públicas para o desenvolvimento do turismo na cidade de Natal e, por outro lado, alia-se aos estudos que procuram compreender os atuais fatores que determinam o comportamento dos turistas na escolha por destinos, por serviços e que contribuem para sua satisfação.

Além disso, quando pesquisado acerca das produções científicas que foram realizadas sobre esse tema na cidade, constatou-se a existência de apenas duas monografias, publicadas, respectivamente, em 2004 e 2014. Por tudo isso, espera-se que esse estudo também possa servir de auxílio e motivação para as próximas produções científicas que venham a ser realizadas sobre este tema, pois essa receptividade de informações dada aos turistas deve ser estudada periodicamente, para que dessa forma a cidade consiga manter um serviço padrão de qualidade.

\section{A PERCEPÇÃO DOS VIAJANTES E A SINALIZAÇÃO DE ORIENTAÇÃO TURÍSTICA}

A compreensão da percepção, sobretudo nos estudos do turismo, tem contribuído para a gestão de destinos e para o incremento em estratégias de marketing turístico (Kotler et al., 2011; Fernandes et al., 2014; Chen et al., 2016). 
No entanto, a percepção que se tem do mundo é diferente para cada indivíduo, uma vez que a realidade é apenas uma, consequentemente a visão pelo homem das coisas materiais é sempre deformada (Santos, 2002).

Tuan (1990) expõe que um aspecto comum entre os seres humanos é que a percepção espacial se dá por meio dos sentidos (visão, tato, audição e olfato), no entanto o autor ressalva que as respostas desses sentidos aos estímulos da realidade objetiva ocorrem de maneira diferente e individualmente. Portanto, as noções de localização e de direção também variam em cada indivíduo. Por isso, a sinalização de orientação turística, destinada a visitantes que normalmente não conhecem a cidade, é um aspecto relevante para o desenvolvimento de atividades turísticas nas cidades.

Swarbrooke e Horner (2016) também enfatizam esse contexto quando afirmam que os turistas são sempre agentes sociais diferentes entre si, o que faz com que também sejam distintos os fatores que os motivam. Além dessa diferenciação entre indivíduos ou grupos culturais de viajantes, vale ressaltar ainda que esses agentes sociais apresentam uma efemeridade (Figueiredo, 2010), já que não constituem uma condição permanente de uma pessoa, mas sim um tipo humano que existe durante a prática do turismo e que se desfaz quando a viagem termina. Portanto, estudar as percepções dos viajantes implica considerar suas características instáveis e momentâneas.

O estudo de Zoderer et al. (2016) demonstra que a percepção espacial dos turistas sobre as paisagens dos lugares visitados varia de acordo com fatores culturais. Assim, os autores ressaltam que a cultura de origem dos turistas serve de referência inicial para as avaliações, valorizações e escolhas que esses viajantes fazem sobre determinados lugares.

Por outro lado, Chen et al. (2016) e Gândara (2008) apontam que há uma inter-relação entre a percepção dos turistas e a satisfação com a experiência tida nos destinos turísticos. Portanto, entre os diversos aspectos de um lugar visitado, a sinalização turística como auxílio para os deslocamentos e obtenção de informações turísticas é um elemento relevante percebido pelos viajantes e um fator importante para a sua satisfação. 
Vale ressaltar, ainda, que a sinalização turística é uma dimensão da infraestrutura que compõe a organização das localidades receptoras, para informar e orientar os moradores e os visitantes quanto às atrações turísticas e aos serviços que mediam as práticas do turismo. Portanto, integra as estratégias de planejamento de destinos turísticos (Souza, 2006; Binfaré et al., 2016).

A sinalização turística, portanto, integra a paisagem com a qual o turista entra em contato e que ajuda a formar a imagem das cidades-destinos turísticos (Fernandes et al., 2014) ao mesmo tempo em que marca e delimita o território turístico (Castro \& Tavares, 2016b), indicando o que deve ser visitado ou que é interessante compor a experiência dos turistas durante suas visitas.

Todavia, vale ressaltar, como expõem Buzinde et al. (2010), que o fenômeno da percepção dos viajantes pode apresentar uma polissemia. Por exemplo, o estudo desses autores aponta que os turistas não necessariamente reagem negativamente a destinos costeiros com problemas de erosão. Assim, discute-se o significado das paisagens construídas por produtores e consumidores desses espaços e, como apontam Castro \& Tavares, (2016a), os elementos materiais e socioculturais têm que ser considerados na compreensão da percepção de lugares usados pelo turismo.

De acordo com Santos (2013, p. 523), a informação sobre um destino é fundamental para a efetivação da demanda turística, segundo o autor "[...] uma vez que produção e consumo do turismo são concomitantes, a demanda turística por um destino é resultado da expectativa de satisfação. Turistas decidem viajar a um local porque esperam satisfazer suas necessidades e desejos".

Dessa forma, para Gândara (2008), são as expectativas geradas antes da viagem que determinarão a satisfação que o turista tem ao longo de sua experiência no destino. Assim, é fundamental que essa imagem corresponda às suas expectativas, nesse caso, a qualidade dos destinos turísticos torna-se imprescindível para essa concretização.

Segundo Lynch (1997), ao se deparar dentro de uma cidade, a pessoa é apoiada pela presença de outros e por planos especiais de orientação; seja de mapas, nomes de ruas, sinais de rota, etc. Com isso, perceber como uma cidade se configura é algo natural, já que se tem essa imagem formada pelo acesso a essas informações e experiências vividas em outras situações. 
Ao se analisar esse posicionamento do autor, pode-se entender que o que irá influenciar diretamente no modo como os turistas percebem a cidade visitada é, principalmente, as experiências passadas que eles carregam consigo no decorrer de suas viagens, podendo ser essas experiências negativas ou positivas.

De acordo com Boullón (2002, p. 194), os ambientes que compõem as cidades, sejam esses naturais ou artificiais, têm linguagem própria, entretanto, "o primeiro se manifesta por si mesmo e o outro é consequência da expressão dos homens". Castrogiovanni (2000, p. 25) vai além desse conceito quando enaltece que, na verdade, "a cidade é o que é visto, mas mais ainda, é o que pode ser sentido".

Nesse sentido, Castro \& Tavares (2016), ao analisarem o processo de turistificação do espaço urbano, ou seja, de transformação de partes da cidade em espaços turísticos, apontam que a sinalização turística é parte importante desse processo, pois apresenta uma marca física no que se configura como território turístico e evidencia aos visitantes onde estão, na cidade, os espaços usados para o turismo.

Todos esses fatores são avaliados pelos turistas em suas viagens e influenciam a percepção geral que terão da cidade como destino turístico, tal como afirma Gândara (2008, p. 8), ao dizer que "a imagem estará determinada pela percepção dos visitantes, que, a sua vez, estará afetada pela acessibilidade à cidade, as condições de qualidade de vida dos residentes e pela direção da política em general".

A sinalização é uma ferramenta integrante da infraestrutura do sistema viário de uma cidade e é responsável por fornecer aos seus usuários todas as informações necessárias sobre o uso correto da via, além de auxiliar nos seus deslocamentos até atingirem o destino pretendido. Em um destino de turismo, a presença de uma sinalização de trânsito é essencial, porém não é suficiente. Os visitantes de uma região turística, além de precisarem fazer uso da sinalização de indicação de trânsito, carecem, ainda, de uma sinalização de orientação turística.

Para Boullón (2002), a razão pela qual os turistas necessitam de um sistema de apoio de informações eficientes sobre a cidade, para que possam conhecer os centros turísticos que visitam, sem o risco de se perder, está associado à grande dificuldade que o homem comum tem de reconhecer esse ambiente. 
Já para Barreto Filho (2000, p. 65-6),

...a sinalização turística facilita a chegada e a saída do turista, assim como seus deslocamentos durante sua estadia em determinado local. O trabalho da sinalização turística deve ser feito nos locais que querem atrair turistas. [...]. As indicações das atrações turísticas são fundamentais para promover roteiros e conscientizar a comunidade.

Portanto, a existência e a eficiência da sinalização turística são fatores fundamentais para que o turista sinta que o destino visitado está pautado no princípio da hospitalidade. Do contrário, a dificuldade de deslocamento e de perceber a localização dos espaços e dos serviços turísticos pode contribuir para uma experiência ultrajante naquele lugar.

No Brasil, a crescente demanda pela população por uma sinalização que facilite o acesso aos atrativos turísticos de um local levou o Instituto Brasileiro de Turismo (EMBRATUR), em parceria com o Departamento Nacional de Trânsito (DETRAN) e o Instituto do Patrimônio Histórico e Artístico Nacional (IPHAN), a elaborar O Guia Brasileiro de Sinalização Turística (GBST) (EMBRATUR, DETRAN \& IPHAN, 2001).

O propósito do manual é tornar referência nacional um modelo de sinalização que possa ser adotado em todo país, agregando mais valor às cidades de interesse turístico e mantendo uma padronização das placas de sinalização passíveis de serem percebidas e entendidas pelos visitantes.

O GBST define a sinalização de orientação turística como "[...] a comunicação efetuada por meio de um conjunto de placas de sinalização, implantadas sucessivamente ao longo de um trajeto estabelecido, com mensagens escritas ordenadas, pictogramasesetas direcionais", eressalta, ainda, que"essa comunicação, que ocorre por meio de placas, deve se dar da forma mais abrangente possível e estar em total conformidade com os demais sistemas de circulação e sinalização viária locais" (EMBRATUR, DETRAN \& IPHAN, 2001, p. 18).

As placas sinalizadoras fornecem as informações sobre a cidade que muitas vezes não estão disponíveis em mapas ou folhetos turísticos. Quanto a essas informações, cabe ressaltar que, segundo Silva \& Mello (2012, p. 132), "[...] é considerada como um dos principais componentes do crescimento da atividade 
turística, pois influencia na interpretação do atrativo, como também na questão do deslocar e do orientar".

Desse modo, é pertinente dizer que a implantação da sinalização turística em uma cidade é imprescindível para um melhor desenvolvimento turístico, porque ela potencializa os atrativos existentes e promove o acesso a eles, seja esse atrativo natural ou cultural.

Além disso, a sinalização exerce grande função na valorização de um local, como afirma Souza (2006, p. 168),

...a sinalização é um elemento de valorização do lugar, devendo ser adequadamente integrada ao planejamento de desenvolvimento do turismo em busca da otimização, da qualidade e da melhoria dos produtos/serviços ofertados aos habitantes do lugar e aos turistas.

De acordo com o GBST, os moradores e os visitantes, ao utilizarem o sistema viário de acesso, assumem várias modalidades de deslocamento durante seus trajetos. Portanto, em certo momento, são motoristas; em outro, são passageiros e depois pedestres, e essa mudança de papéis desperta interesses diferentes: de fluidez no tráfego, de facilidade para estacionamento e de segurança ao caminhar pelas vias (EMBRATUR, DETRAN \& IPHAN, 2001).

Desse modo, a sinalização de orientação turística elaborada pela EMBRATUR, pelo DETRAN e pelo IPHAN apresenta algumas características específicas para diferenciá-la dos outros tipos de sinalização. Nesse caso, as placas de sinalização turística são padronizadas pela cor marrom, porque estas já são reconhecidas e utilizadas na maioria dos países como indicativas de bens e serviços turísticos e patrimoniais, além do estabelecimento de pictogramas, que foram desenvolvidos para facilitar o entendimento das informações contidas nas placas.

O GBST define o pictograma para a sinalização turística da seguinte forma:

Corresponde às ilustrações que sintetizam os tipos de atrativo turístico e de serviço auxiliar, cujo uso é recomendado para facilitar a identificação do destino, complementando a função do topônimo e melhorando o esquema de comunicação com o usuário. 0 pictograma deve ser de fácil identificação a distância, constituído por um símbolo na cor preta, sobre campo na forma quadrada de cor 
O desenvolvimento de pictogramas específicos para a sinalização turística é muito importante porque, além de os pictogramas facilitarem o entendimento das informações acopladas nas placas, também auxiliam na comunicação para aqueles que falam outro idioma, democratizando, dessa forma, o acesso aos atrativos turísticos de um local.

De acordo com o Guia, a apresentação dos pictogramas é dividida em sete grupos: atrativos turísticos naturais; atrativos históricos e culturais; áreas para prática de esporte; áreas de recreação; locais para atividade de interesse turístico; serviços de transporte e serviços variados.

A implantação de uma sinalização turística em determinado destino deve, antes de tudo, levar em consideração a avaliação das questões urbanas do local, já que essa avaliação é mais complexa por se tratar de uma situação em permanente mudança. O GBST ainda aponta que nessa avaliação também devem ser consideradas a lei de uso do solo e a lei dos sistemas viário e de transporte.

Um dos objetivos do Guia é promover a sustentabilidade do local a ser sinalizado. Dessa forma, o documento traz duas modalidades de acesso que precisam ser cautelosamente estudadas para uma melhor implantação dessa sinalização.

$\mathrm{Na}$ modalidade de acesso feito por veículo motorizado - objetivo central desse estudo -, é fundamental a escolha de um sistema viário com capacidade suficiente para a circulação e, ao mesmo tempo, compatível com as políticas de desenvolvimento e de organização territorial, especialmente quando os trajetos se encontram em áreas urbanas tombadas ou protegidas por alguma legislação (EMBRATUR, DETRAN \& IPHAN, 2001).

Em contrapartida, a utilização de um sistema viário inadequado e a seleção equivocada dos atrativos podem levar a população local a reagir negativamente à circulação de turistas. Diante disso, fica evidente o quanto a sinalização de orientação turística é importante para promover os melhores caminhos a serem seguidos, integrando cada vez mais o turista aos atrativos e às outras atividades da cidade. 
A pesquisa desenvolvida caracteriza-se como um estudo exploratório que, seguindo princípios encontrados em Stylidis, Sit \& Biran (2016), procurou identificar e testar as dimensões da percepção sobre a sinalização de orientação turística, diante da carência de estudos que abordem essa temática. Desta forma, este estudo utilizou como instrumento de coleta de dados um questionário estruturado, com perguntas objetivas e fechadas, desenvolvido com base nas dimensões apresentadas no Guia Brasileiro de Sinalização Turística (GBST) (EMBRATUR, DETRAN \& IPHAN, 2001).

Os questionários foram preenchidos pelos pesquisadores, em entrevistas com viajantes locatários de veículos que estiveram em visita à cidade de NatalRN. Por isso, a sala de desembarque do Aeroporto Internacional Governador Aluízio Alvez, na Região Metropolitana de Natal-RN, foi escolhida para a coleta dos dados, visto que muitas empresas que oferecem o serviço de aluguel de automóveis encontram-se no local, que também é o lugar de devolução dos automóveis locados e terminal de acesso para a viagem de retorno após a visita ao destino Natal, adequando-se aos objetivos de investigação estabelecidos para este trabalho. Assim, foram preenchidos um total de 124 questionários no período que compreendeu os dias 28 de abril ao dia 01 de maio de 2016.

Os questionários foram estruturados com oito perguntas fechadas, que foram as perguntas de identificação dos respondentes e as perguntas da pesquisa sobre a sinalização turística. Essas foram estruturadas com cinco questões em escala Likert de cinco níveis, compreendendo a apresentação de afirmações aos entrevistados, sobre as quais esses sujeitos apresentam seu posicionamento se descordam plenamente, descordam parcialmente, são indiferentes, concordam parcialmente ou concordam plenamente, como indicam Trentin e Silva (2010) e Hasrtley (2014).

À vista disso, a elaboração dessas questões foi formulada com base em alguns dos princípios básicos estabelecidos no GBST, como se apresenta sintetizado na tabela a seguir. 
Tabela 1: Relação entre os princípios da sinalização turística e as questões formuladas para os viajantes entrevistados

Princípio

Padronização

Visibilidade, legibilidade e segurança

Suficiência

Continuidade e coerência

Manutenção e conservação
Questão formulada

As placas de sinalização turística são todas padronizadas; possuem a cor marrom e formas que permitem a correta assimilação das informações turísticas.

A visualização das placas de sinalização turística é clara e pode ser lida a uma distância de forma segura.

As informações contidas nas placas de sinalização oferecem todas as informações necessárias para atingir os destinos pretendidos e auxiliam na adaptação às diversas situações viárias.

As placas de sinalização turística são contínuas e mantêm coerência nas informações.

As placas de sinalização turística são bem conservadas; todas estão limpas, bem fixadas e corretamente iluminadas.

Nota. Dados da pesquisa, 2016.

A partir de cada questão formulada, os respondentes puderam escolher seu grau de concordância ou discordância numa escala de valor que variou de cinco a um, de maneira que cinco é para "concordo totalmente" e um para "discordo totalmente", além de uma opção neutra "não concordo nem discordo".

A técnica de análise usada para este questionário foi estatística descritiva, a partir de princípios norteadores estabelecidos em Holcomb (2017), portanto as respostas coletadas foram posteriormente lançadas em uma planilha eletrônica para a obtenção desses valores numéricos, e os percentuais foram arredondados para valores absolutos aproximados e correspondentes.

O estudo partiu da hipótese de que a percepção dos viajantes locatários de veículos sobre a sinalização turística de Natal é, em geral, negativa, provocando insatisfação desses viajantes com esse aspecto da infraestrutura turística da cidade.

\section{RESULTADOS E DISCUSSÕES}

\section{O PERFIL DOS VIAJANTES PESQUISADOS}

Por meio das respostas obtidas com a aplicação dos 124 questionários, verificou-se que a maioria dos respondentes (56\%) é do sexo masculino e 
44\%, do sexo feminino. A Tabela 2 apresenta a distribuição da amostra por faixa etária.

Tabela 2: Faixa etária dos viajantes entrevistados

Idade

21 a 31

32 a 41

42 a 51

Acima de 52

Total
$\mathrm{N}^{\circ}$ de entrevistados

60

46

6

12

124
Percentual da amostra

$48 \%$

$37 \%$

$5 \%$

$10 \%$

$100 \%$

Nota. Dados da pesquisa, 2016.

Sobre o grau de escolaridade pôde ser constatado que o ensino superior completo representou um dos números mais expressivos desta pesquisa, comportando um total de $71 \%$. Ademais, foi verificado que $13 \%$ possuem ensino superior incompleto, $13 \%$ têm ensino médio completo, $2 \%$ médio incompleto e apenas uma pessoa entrevistada possuía ensino fundamental completo (1\%).

Em relação à procedência desses sujeitos, foi percebido que a maioria dos respondentes vem da região Sudeste do Brasil. Em percentuais aproximados, constatou-se que os viajantes provenientes dos Estados de São Paulo (35\%) e Rio de Janeiro (22\%) representaram mais da metade dessa população. Logo em seguida, dentre os demais estados brasileiros, destacaram a presença de Santa Catarina (7\%), Paraná (6\%), Paraíba (6\%) e Rio Grande do Sul (6\%). Os viajantes procedentes do Distrito Federal (4\%) e dos Estados Ceará (4\%), Pará (4\%), Minas Gerais (2\%), Pernambuco (2\%), Bahia (2\%) e Goiás (1\%) também estiveram presentes na amostra, no entanto em menor número.

Quando os viajantes foram questionados sobre o motivo que os levou a ter vindo para Natal, certificou-se que predominam os viajantes que visitaram a cidade por motivos de lazer (89,4\%), uma parte menor dos entrevistados estive na cidade por motivos relacionados a negócios (9\%) e apenas duas pessoas estavam na cidade para visitar família e/ou amigos (1,6\%).

PADRONIZAÇÃO

Seguindo a ordem dos critérios analíticos estabelecidos no GBST, a padronização foi o primeiro quesito que os respondentes avaliaram. Neste ponto, foram levados em consideração o conjunto de placas de sinalização turística existente na cidade. 
É muito importante, nesse aspecto, que esse conjunto de placas esteja da mesma cor e que haja uma padronização de suas formas.

O GBST recomenda que as placas que constituem a sinalização de orientação turística obedeçam a um conjunto de critérios que objetivem garantir sua imediata identificação e a correta assimilação das mensagens que veiculam. É essa obediência aos princípios de aplicação das placas que garantem a eficácia da sinalização.

Dessa maneira, os resultados da pesquisa neste critério mostraram que, de um modo geral, a percepção da sinalização turística referente à padronização das placas apresentou um resultado bastante positivo para esses viajantes.

Como se pode observar na Figura 1,92\% manifestam que percebem a padronização das placas de sinalização turística na cidade, sendo que desses 92\%, 61\% afirmaram estar totalmente de acordo que haja essa padronização.

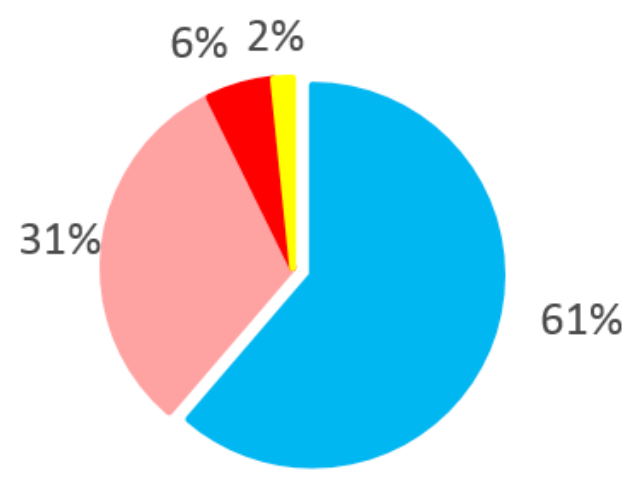

Concordo totalmente (61\%)

Concordo parcialmente (31\%)

não concordo nem discordo (6\%)

Discordo parcialmente (2\%)

Figura 1. Distribuição das respostas sobre a percepção da sinalização turística, quando afirmado que é apresentada de modo padronizada.

Vale ressaltar que essa dimensão da análise diz respeito a um aspecto estritamente técnico, que é a obediência da sinalização à normatização existente. Sobre esse aspecto, a percepção do viajante pode remeter-se ao que foi visto em outros destinos turísticos ou a uma impressão imediata, que não necessariamente diz respeito ao conhecimento dos aspectos normativos envolvidos.

Com base nesses resultados, pode-se perceber que a padronização das placas de sinalização turística em Natal é passível de ser percebida pelos visitantes, como vislumbrado nos dados apresentados anteriormente, é notória a satisfação dessas pessoas em relação a esse critério avaliado. 


\section{VISIBILIDADE, LEGIBILIDADE E SEGURANÇA}

Nesta segunda dimensão analítica, os viajantes puderam manifestar sua percepção se as mensagens contidas nas placas e seus respectivos elementos podem ser visualizados claramente, independente das características das vias e das velocidades nelas regulamentadas. Sendo assim, é muito importante que essas placas estejam bem fixadas e que sua disposição nas vias mantenham uma distância que permita a visualização rápida, a fim de ser lida de forma segura, para que os usuários das vias tenham tempo hábil para a sua tomada de decisão e, assim, evitar hesitação e manobras bruscas.

Esse critério exige bastante atenção, já que as dimensões analisadas são elementos indispensáveis para esses viajantes. Nesse sentido, os resultados da pesquisa, neste aspecto, demonstram que, de modo geral, os viajantes têm uma percepção satisfatória.

Como pode ser analisado na Figura 2, 78\% afirmaram estar de acordo com a eficiência da visibilidade, da legibilidade e da segurança das placas de sinalização, sendo que a maioria, $48 \%$ do total, disse estar apenas parcialmente de acordo com essa assertiva. A minoria, que foi de $9 \%$, posicionou-se negativamente a essa afirmação, e as pessoas que afirmaram indiferença foram $13 \%$ do total das entrevistas.

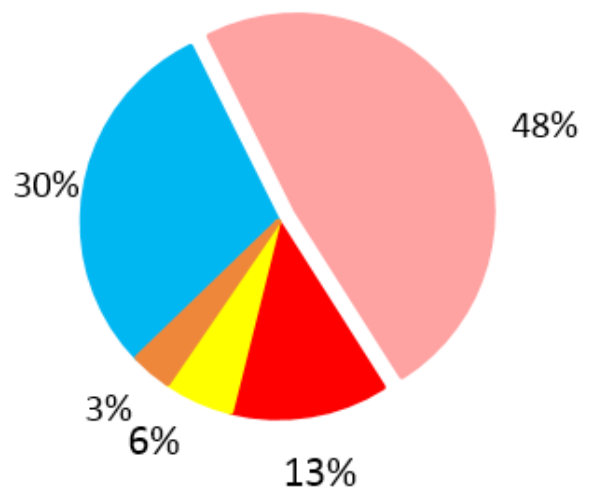

Concordo totalmente (30\%)

Concordo parcialmente (48\%)

— Não concordo nem discordo (13\%)

Discordo parcialmente (6\%)

Discordo totalmente (2\%)

Figura 2. Distribuição das respostas sobre a percepção da sinalização turística, quando afirmado que a sinalização é clara e pode ser lida a uma distância de forma segura.

Esses dados demonstram que, para a maioria dos viajantes, a sinalização turística na cidade cumpre, de maneira satisfatória, o seu dever de indicar de forma segura e inteligível os melhores trajetos a serem seguidos. Com isso, 
pode-se entender que a aplicação das placas de sinalização nas vias, bem como a sua fixação e suporte, faz jus aos critérios exigidos pelo GBST.

\section{SUFICIÊNCIA}

Durante a análise deste critério, os respondentes avaliaram a questão da qualidade e da quantidade das mensagens contidas nas placas de sinalização e também no seu auxílio à adaptação às diversas situações viárias do local.

Aqui, torna-se indispensável que o conjunto de informações contidas nas placas indiquem a melhor direção a seguir, a informação sobre a distância a ser percorrida até determinado destino ou a confirmação de ter chegado onde se pretendia. Em outras situações, ainda são convenientes o tipo e a quantidade de informações diferenciadas, que propiciem fluidez e segurança de trânsito ou que transmitam detalhes sobre a região e seus atrativos.

Um fato observado após a avaliação dos questionários foi um equilíbrio de satisfação entre as extremidades positiva e negativa. Assim, 54\% avaliaram positivamente a suficiência das mensagens contidas nas placas. Entretanto, apenas $16 \%$ desse valor está totalmente de acordo. Do outro lado, 30\% das pessoas entrevistadas discordam que as mensagens contidas nas placas de sinalização são suficientes para garantir o acesso aos destinos pretendidos. $\mathrm{E}$ as pessoas que se posicionaram totalmente em desacordo com essa afirmação correspondem a $10 \%$ do total de entrevistados.

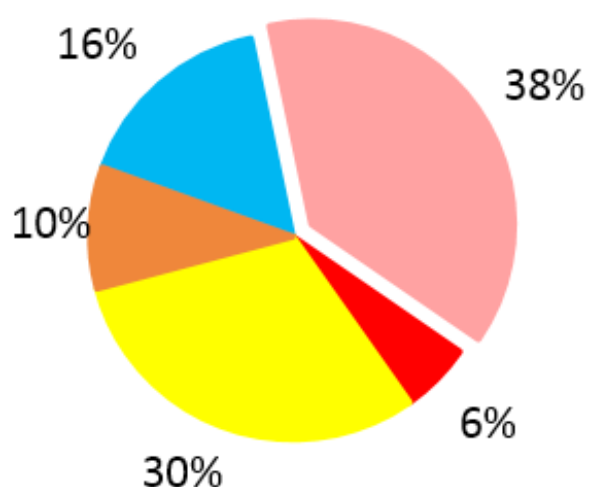

Concordo totalmente (16\%)

Concordo parcialmente (38\%)

não concordo nem discordo (6\%)

Discordo parcialmente (30\%)

Discordo totalmente (10\%)

$30 \%$

Figura 3. Distribuição das respostas sobre a percepção da sinalização turística, quando afirmado que as informações contidas na sinalização oferecem todas as informações necessárias. 
De acordo com esses resultados, fica evidente que a suficiência da sinalização é percebida como parcialmente suficiente, pois o fato de a maioria (56\%) dos respondentes da pesquisa ter manifestado impressões positivas quanto a esse aspecto da sinalização turística é confrontado com a percepção negativa que outra parcela considerável (40\%) dos entrevistados tem.

Observa-se, então, que a sinalização de orientação turística presente é um aspecto da infraestrutura para a cidade e para o turismo que proporciona garantia de um deslocamento eficaz dentro da cidade, todavia apresenta problemas percebidos pelos visitantes que precisam ser levados em consideração para seu aprimoramento.

\section{CONTINUIDADE E COERÊNCIA}

Neste critério alguns princípios básicos que foram avaliados pelos respondentes referem-se à continuidade da informação, que repercute na credibilidade da sinalização por parte dos usuários. Julga-se dizer que esse é um dos objetivos principais de uma sinalização turística, afinal a continuidade das mensagens visa garantir a realização de todos os deslocamentos previstos com a ajuda da sinalização e não induzir o usuário da via ao erro ou à dúvida.

Ainda é relevante enfatizar que as distribuições das placas de sinalização turística não obstruem a visualização de paisagens e monumentos, tanto para usuários de veículos motorizados quanto para ciclistas e pedestres.

Com isso, dos que aprovaram totalmente a sinalização nesse ponto, foi um número muito baixo, de apenas $14 \%$ do total. Observa-se que a maioria se posicionou apenas parcialmente de acordo (35\% do total). Ainda assim, é notória a insatisfação de grande parte desses sujeitos neste critério. Em meio a essas opiniões, $46 \%$ discordaram que existe continuidade nas mensagens das placas e coerência entre elas. Dos que desaprovam a sinalização nessa avaliação, 15\% afirmaram estar totalmente insatisfeitos com a continuidade e coerência dessas placas. 


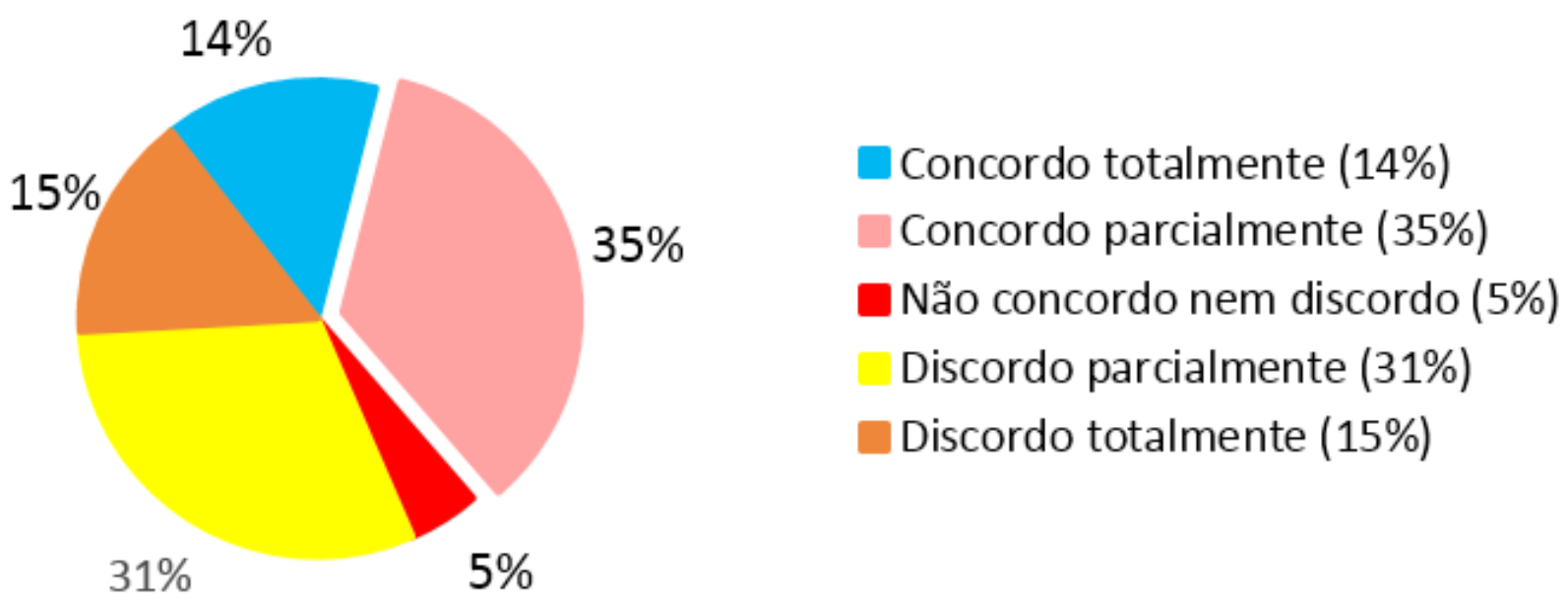

Figura 4. Distribuição das respostas sobre a percepção da sinalização turística, quando afirmado que as placas de sinalização turística são contínuas e mantêm coerência nas informações.

Considerando a relevância desse aspecto da sinalização turística, sobretudo para atingir os objetivos de auxiliar no deslocamento dos visitantes pelos serviços e atrativos turísticos da cidade, observa-se que, por mais que os viajantes percebam a existência dessa sinalização, é igualmente notada por esses sujeitos uma considerável descontinuidade dessa fonte de informação turística, que se apresenta como uma dimensão que pode ser aprimorada na cidade como destino turístico.

\section{MANUTENÇÃO E CONSERVAÇÃO}

As placas de sinalização de orientação turística devem ser periodicamente submetidas a uma manutenção para corrigir danos, sujeiras ou deformações, que provocam a ineficácia e formam uma imagem de descrédito da entidade responsável. Além disso, essa manutenção é importante também para preservar a sua conservação, pois placas de sinalização sem conservação ou com conservação precária perdem sua eficiência como dispositivos de auxílio ao tráfego dos visitantes das cidades. Ainda é imprescindível que as autoridades de trânsito assegurem que a vegetação, o mobiliário urbano, as placas publicitárias e os materiais de construção não prejudiquem a visualização das placas, mesmo que temporariamente. 
Os resultados dessa pesquisa nesse quesito mostraram que, embora tenham sido observadas algumas críticas sobre a sinalização turística nos critérios analíticos que o antecederam, o critério analisado referente à manutenção e à conservação é percebido pela maioria dos viajantes positivamente. Como pode ser observado na Figura 5, o total de aprovação desse critério foi de $72 \%$, enquanto $13 \%$ apresentaram percepção negativa a respeito dessa dimensão.

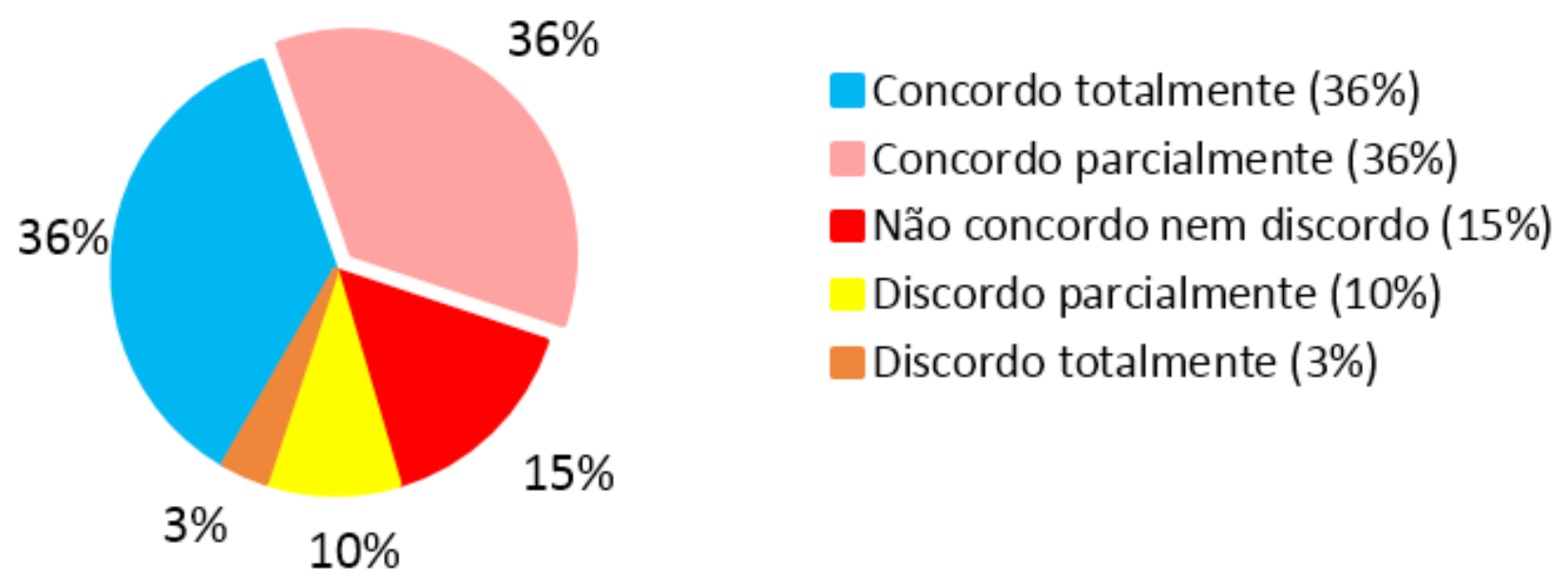

Figura 5. Distribuição das respostas sobre a percepção da sinalização turística, quando afirmado que a sinalização é bem conservada.

Apesar da sinalização turística apresentar algumas falhas em sua maioria no quesito "suficiência" e "continuidade e coerência", a conservação das placas dessa sinalização revelou-se satisfatória. E ainda é razoável dizer que essa aprovação contribuiu para a satisfação geral dos viajantes sobre esse serviço prestado pela cidade.

\section{SÍNTESE INTEGRADA DA PERCEPÇÃO SOBRE A SINALIZAÇÃO TURÍSTICA}

Nesta parte, apresenta-se uma síntese da percepção dos viajantes pesquisados, integrando as cinco dimensões da sinalização turística investigada. A Figura 6 demonstra que, em geral, a sinalização turística da cidade de Natal teve uma percepção predominantemente positiva entre os visitantes locatários de veículos, que transitaram por lugares turísticos do destino. 


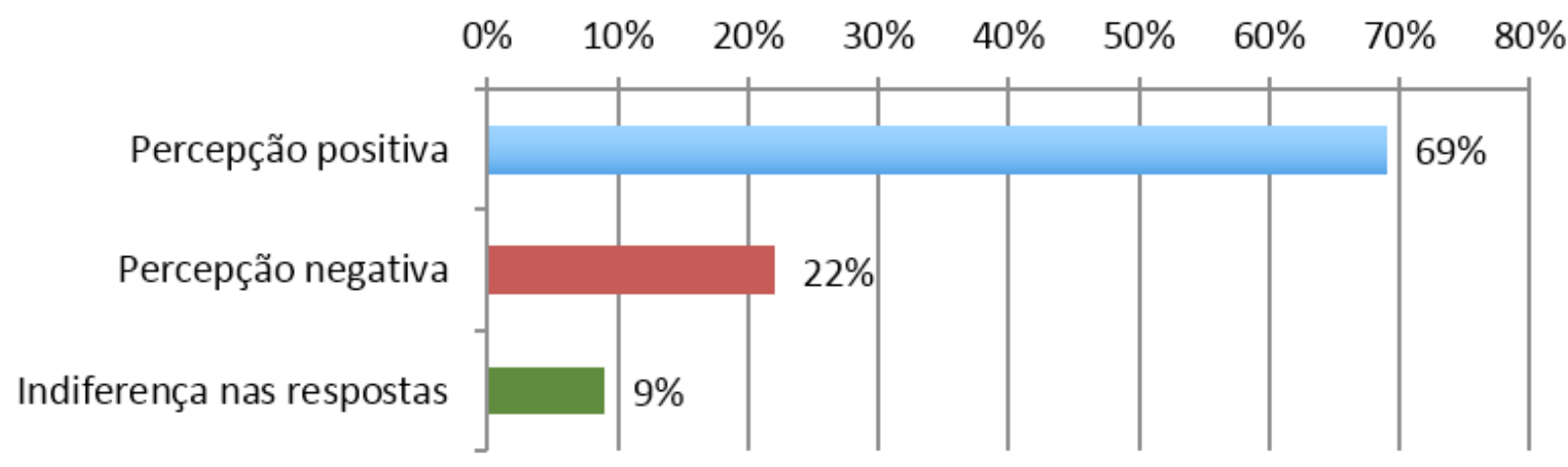

Figura 6. Distribuição da média das respostas sobre as cinco dimensões da sinalização turística utilizadas na análise dos dados.

É possível, então, notar que a maioria dos entrevistados (69\%) apresentou, em média, uma percepção positiva das dimensões adotadas para analisar a sinalização turística, enquanto a percepção negativa sobre essa parte da infraestrutura turística de Natal-RN foi, em média, minoritária (22\%).

Vale ressaltar, ainda, que o nível de indiferença nas respostas às escalas estabelecidas pela pesquisa foi baixo (9\%), o que revela que os entrevistados, em grande parte, procuraram expressar sua percepção (positiva ou negativa) sobre os aspectos investigados.

\section{A SATISFAÇÃO GERAL DOS VIAJANTES COM A SINALIZAÇÃO DE ORIENTAÇÃO TURÍSTICA}

Neste ponto, foi levado em consideração o grau de satisfação dos viajantes, em âmbito geral, acerca da sinalização turística de Natal-RN. Portanto, a avaliação geral quanto à satisfação com a sinalização turística de Natal-RN é de que $57 \%$ do total de pessoas consideram-se satisfeitas, enquanto $14 \%$ manifestaram insatisfação com essa parte da infraestrutura turística da cidade, conforme apresentado na Figura 7.

Além disso, vale ressaltar que foi considerável o número de pessoas que se posicionaram como neutras em relação a essa satisfação (29\%). Esse número foi consideravelmente maior do que a neutralidade nas respostas das cinco dimensões da sinalização turística analisadas (9\%). 


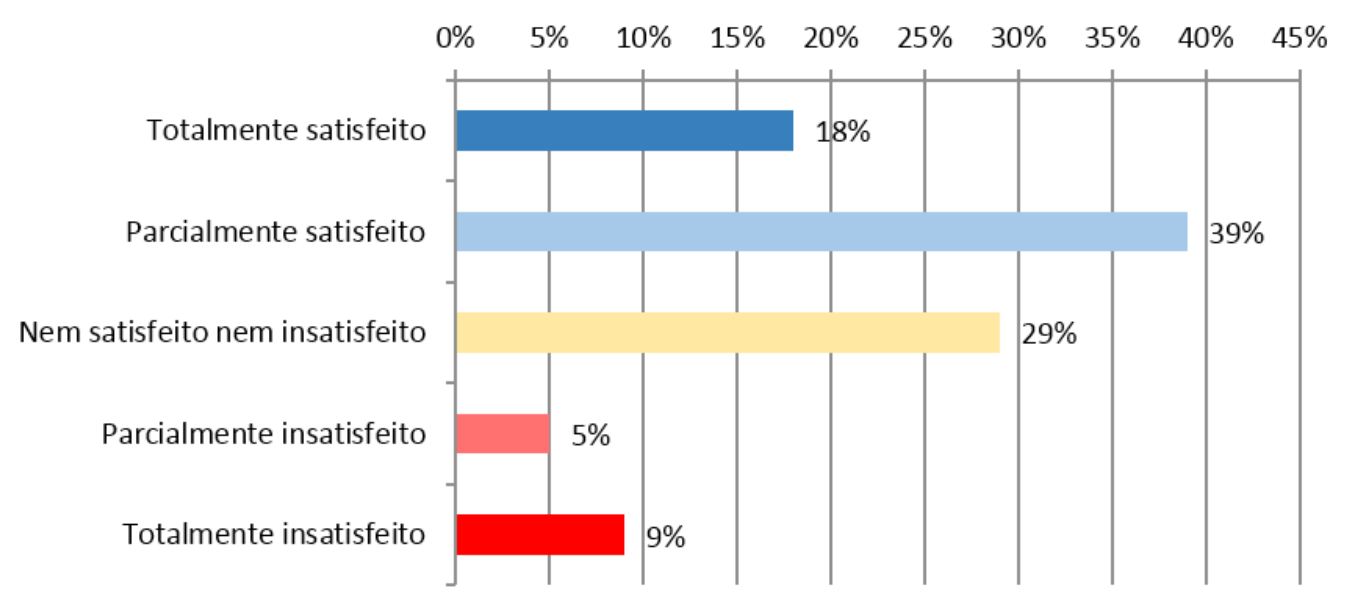

Figura 7. Distribuição das respostas sobre a avaliação geral da satisfação geral dos viajantes com a sinalização turística, quando afirmado que a sinalização é clara e pode ser lida a uma distância de forma segura.

Entretanto, como já citado anteriormente, de modo geral, a sinalização turística da cidade, embora tenha apresentado seus impasses, foi percebida como predominantemente boa. Ainda que a sinalização tenha apresentado críticas negativas em alguns critérios analíticos aqui avaliados, pôde-se perceber que esses impasses não chegaram a influenciar com tanta veemência na satisfação geral acerca dessa sinalização.

\section{CONSIDERAÇÕES FINAIS}

Os resultados apontam para a percepção da existência de sinalização turística, sobretudo atrelada à sinalização geral de trânsito. Todavia também são percebidas ineficiências dessa sinalização como ferramenta de apoio aos deslocamentos e ao acesso dos visitantes de Natal a atrativos, estruturas e serviços turísticos da cidade.

O objetivo principal do estudo aqui proposto foi compreender a percepção dos viajantes sobre a sinalização de orientação turística em Natal, tendo como enfoque os princípios básicos estabelecidos no Guia Brasileiro de Sinalização Turística. Sendo assim, constatou-se que o resultado foi bastante positivo no que diz respeito aos termos técnicos aplicados nas placas, pois foi visto que os resultados mais satisfatórios se concentraram nos critérios "padronização", "visibilidade, legibilidade e segurança" e "manutenção e conservação". 
Esses três critérios tinham por finalidade verificar se o conjunto dessas placas de sinalização seguiam o padrão estabelecido no GBST quanto a cores e formas, se elas podiam ser vistas e lidas a uma distância de forma segura e se estavam bem conservadas; ou seja, limpas e bem fixadas. Então, com base nos resultados dessa percepção, foi verificado que o material das placas, bem como a sua conservação e os princípios de aplicação nas estradas, cumprem, de modo satisfatório, as normas estabelecidas no Guia.

Já os resultados no que concerne aos critérios "suficiência" e "continuidade e coerência" não apresentaram um dado tão satisfatório quanto aos outros critérios aqui examinados. Desta forma, no decorrer do estudo, percebeu-se que os viajantes estão menos satisfeitos com a sinalização no que se refere ao conteúdo das placas; bem como a sequência de placas nas vias e a quantidade das informações. Essa é uma das questões mais críticas observadas neste estudo, já que, para uma grande parcela dos viajantes entrevistados, a sinalização não cumpriu um dos princípios básicos estabelecidos no GBST, quando asseverou que "[...] manter a continuidade das mensagens visa garantir a realização de todos os deslocamentos previstos pela sinalização e não induzir o usuário da via ao erro ou à dúvida, o que possibilitaria a ocorrência de acidentes" (EMBRATUR; IPHAN; DETRAN, 2001, p 28).

Ainda que os problemas mais graves percebidos estivessem concentrados nos critérios "suficiência" e "continuidade e coerência", quando analisado o todo, é perceptível que a satisfação desses viajantes apresentou ambiguidades em cada critério aqui avaliado e, com isso, é plausível dizer que as falhas também são. Dessa maneira, pode-se concluir que a sinalização turística da cidade é, em parte, deficitária.

Além disso, fatores como a predominância de respondentes com idade entre 21 e 31 anos (48\%), incongruências entre níveis elevados de percepção positiva de itens ligados à percepção da existência da sinalização turística (padronização, visibilidade e manutenção) e diminuição desses níveis com relação à percepção da eficiência dessa sinalização ao propósito de auxiliar os viajantes (suficiência e continuidade), e considerável número de respostas neutras (29\%) quanto à satisfação geral com essa sinalização permitem indicar futuros estudos que 
ISSN: 1983-7151

analisem outras fontes de informações aos turistas, sobretudo os dispositivos e as tecnologias de informações móveis, como abordam os estudos de Chen, Han \& Joun (2015) e Mendes Filho et al. (2017).

Ademais, o estudo também permitiu verificar que as dimensões utilizadas para a análise da percepção de viajantes sobre a sinalização turística mostraramse suficientes e contribuem para a compreensão da satisfação de turistas com esse aspecto da estrutura turística de um destino.

Por tudo isso, não é cabível dizer que a utilização dessa sinalização é um instrumento que proporciona um deslocamento eficaz dentro da cidade. Por isso, ao observar essa irregularidade na sinalização turística por meio da percepção desses viajantes e, ao observar o quanto que a atividade do turismo é importante para o desenvolvimento econômico de Natal, é imprescindível que as lideranças públicas da cidade atentem a essa questão, pois, como visto anteriormente, a sinalização de orientação turística, se bem implantada, tem a capacidade de trazer inúmeros benefícios, tanto para os habitantes do local quanto para os visitantes; além de trazer uma organização para a cidade e, também, contribuir para o marketing do local, sendo esse um fator fundamental para a satisfação e fidelização desses visitantes.

\section{REFERÊNCIAS}

Barreto Filho, A. (2011). Marketing turístico para o espaço urbano: comentários acadêmicos e profissionais. In: A. Castrogiovanni (Org). Turismo urbano (pp. 61-67). São Paulo: Contexto. Barretto, M. (1991). Planejamento e organização em turismo. Campinas: Papirus.

Binfaré, P., Castro, C., Silva, M., Galvão, P., \& Costa, S. (2016). Planejamento turístico: aspectos teóricos e conceituais e suas relações com o conceito de turismo. Revista de Turismo Contemporâneo, 4(Edição Especial), 24-40. Recuperado de https://periodicos.ufrn. br/turismocontemporaneo/article/view/6042/6411

Boullón, R. (2002). Planejamento do espaço turístico. São Paulo: Edusc.

Buzinde, C., Manuel-Navarrete, D., Yoo, E., \& Morais, D. (2010). Tourists' perceptions in climate of change: eroding destinations. Annals of Tourism Research, 37(2), 333-354. doi: 10.1016/j.annals.2009.09.006 
Castro, C., \& Tavares, M. (2016a). A patrimonialização como processo de produção social do espaço urbano. Sociedade e Território, 28(2), 117-135. Recuperado de https://periodicos. ufrn.br/sociedadeeterritorio/article/view/9553/8163

Castro, C., \& Tavares, M. (2016b). Processos de turistificação do espaço do patrimônio cultural: um estudo no Centro Histórico de Belém-PA. Revista Turismo Estudos \& Práticas, 5(1), 5787. Recuperado de https://periodicos.ufrn.br/sociedadeeterritorio/ article/view/9553/8163

Castro, V., \& Castro, C. (2015). A Gestão Pública do lazer em espaços públicos urbanos: um estudo de caso da Praça do Operário, no município de Breves-PA. Revista Brasileira de Estudos do Lazer, 2(3), 139-158. Recuperado de https://seer.ufmg.br/index.php/ rbel/article/view/1702/2118

Castrogiovanni, A. (2000). Turismo e ordenação do espaço urbano. In: A. Castrogiovanni (Org.). Turismo urbano (pp. 23-32). São Paulo: Contexto.

Chen, C., Chen, S., Lee, H., \& Tsai, T. (2016). Exploring destination resources and competitiveness. A comparative analysis of tourists' perceptions and satisfaction toward an island of Taiwan. Ocean \& Coastal Management, 119, 58-67. Doi: 10.1016/j.ocecoaman.2015.09.013

Chung, N., Han, H., \& Joun, Y. (2015). Tourists' intentions to visit a destination: The role of augmented reality (AR) application for a heritage site. Computers in Human Behavior, 50, 588-599. Doi: 10.1016/j.chb.2015.02.068

Fernandes, D., Souza, T., Tonon, L., \& Gândara, J. (2014). A paisagem urbana e a formação da imagem turística da cidade de Curitiba/PR: a percepção de visitantes e visitados. Revista Hospitalidade, 11(1), 45-63. Recuperado de https://www.revhosp.org/hospitalidade/ article/view/511/559

Figueiredo, S. (2010). Viagens e viajantes. São Paulo: Annablume.

Gândara, J. (2008). A imagem dos destinos turísticos urbanos. Revista Eletrônica de Turismo Cultural, (Especial), 1-22. Recuperado de http://www.eca.usp.br/turismocultural/ aimagem.pdf

Hartley, J. (2014). Some thoughts on Likert-type scales. International Journal of Clinical and Health Psychology, 14(1), 83-86. doi: 10.1016/S1697-2600(14)70040-7

Holcomb, Z. (2017). Fundamentals of descriptive statistics. Oxon: Routledge.

Instituto Brasileiro de Turismo, Instituto do Patrimônio Histórico e Artístico Nacional, \& Departamento Nacional de Trânsito. (2001). Guia brasileiro de sinalização turística. Recuperado de: http://www.bancodevideos.turismo.gov.br/guia/conteudo/principal. html

Kotler, P., Bowen, J., Makens, J., Madariaga, J., \& Zamora, J. (2011). Marketing turístico. Madrid: Perason.

Lynch, K. (1997). A imagem da cidade. São Paulo: Martins Fontes.

Mendes Filho, L., Batista, J., Cacho, A., \& Soares, A. (2017). Aplicativos móveis e turismo: um estudo quantitativo aplicando a Teoria do Comportamento Planejado. Revista Rosa dos 
ISSN: 1983-7151

Ventos - Turismo e Hospitalidade, 9(11), 179-199. Recuperado de http://www.ucs.br/etc/ revistas/index.php/rosadosventos/article/view/4787/pdf

Ministério do Turismo. (2015). Índice de Competitividade do Turismo Nacional. Natal 2015. Brasília: Autor. Recuperado de http://www.turismo.gov.br/sites/default/turismo/o_ ministerio/publicacoes/Indice_competitividade/2015/Natal_RA_2015.pdf

Santos, G. (2013). O que determina a satisfação dos turistas internacionais no Brasil? Revista Turismo em Análise, 24(3), 521-543. Doi: 10.11606/issn.1984-4867.v24i3p521-543

Santos, M. (2002). Manual de geografia urbana. São Paulo: Edusp.

Silva, F., \& Melo, R. (2012). A contribuição da sinalização turística para o desenvolvimento turístico da cidade de Parnaíba (PI, Brasil). Revista Brasileira de Pesquisa em Turismo, 6(2), 129-146. Doi: 10.7784/rbtur.v6i2.488

Souza, M. (2006). Sinalização turística e percepção do espaço geográfico. Revista Turismo Visão e Ação, 8(1), 165-176. Doi: 10.14210/rtva.v8n1.p165-176

Stylidis, D., Sit, J., \& Biran, A. (2016). An exploratory study of residents'perception of place image. The case of Kavala. Journal of Travel Research, 55(5), 659-674.

Swarbrooke, J., \& Horner, S. (2016). Consumer behaviour in tourism. Oxon: Routledge.

Trentin, F., \& Silva, E. (2010). Motivos para escolha do curso de Turismo. Revista Turismo Visão e Ação, 12(2), pp. 204-2015. Doi: 10.14210/rtva.v12n2.p204-215

Tuan, Y. (1990). Topophilia. A study of environmental perception, attitudes and values. New York: Columbia University Press.

Zoderer, B., Tasser, E., Karl-Heinz, E., Stanghellini, P., \& Tappeiner, U. (2016). Identifying and mapping the tourist perception of cultural ecosystem services: A case study from an Alpine region. Land Use Policy, 56, 251-261. Doi: 10.1016/j.landusepol.2016.05.004

\section{CONTRIBUIÇÃO DOS AUTORES NA CONSTRUÇÃO DO ARTIGO}

DA SILVA: Fundamentação teórica inicial, coleta e análise dos dados, redação.

CASTRO: Atualização e revisão da fundamentação teórica, análise dos dados e revisão da redação. 